\title{
Erratum: Inferolateral Transorbital Approach to the Petrous Apex. An Adjunctive Approach to the EEA
}

Moustafa Ali ${ }^{1,2}$ Janmaris Marin ${ }^{1}$ Daniel Prevedello ${ }^{1}$ Bradley Otto ${ }^{1}$ Ray Cho ${ }^{1}$ Ricardo Carrau ${ }^{1}$

${ }^{1}$ Ohio State University, Columbus, Ohio, United States

${ }^{2}$ Assiut University, Egypt

J Neurol Surg B 2020;81:e1.

\section{ERRATUM}

It has been brought to the Publisher's attention that the name of "Janmaris Marin" was published incorrectly in the abstracts supplement of the Journal of Neurological Surgery Part B, volume 81 (S 01) on page S185. DOI of the article is DOI: 10.1055/s-0040-1702612. The name has now been updated in the author byline. 